\title{
UMA CÉlula ELETROQUímiCA DE FLUXO PARA MODIFICAÇÃo PERMANENTE DE TUBO DE GRAFITE EMPREGADO EM ABSORÇÃO ATÔMICA
}

Ruben G. M. Moreno, Elisabeth de Oliveira, Pedro V. Oliveira*

Instituto de Química, Universidade de São Paulo, Av. Prof. Lineu Prestes, 748, 05508-901 São Paulo - SP

Jairo J. Pedrotti

Departamento de Química, Faculdade de Ciências Biológicas, Exatas e Experimentais, Universidade Presbiteriana Mackenzie, R. Itambé, 45, 01239-900 São Paulo - SP

Recebido em 20/7/00; aceito em 29/9/00

\begin{abstract}
AN ELECTROCHEMICAL FLOW CELL FOR PERMANENT MODIFICATION OF GRAPHITE TUBE EMPLOYED IN ATOMIC ABSORPTION. A flow cell assembled on the original geometry of a graphite tube to achieve permanent chemical modifier is proposed. The graphite tube operates as the working electrode. A stainless steel tube, positioned downstream from the working electrode, was used as the auxiliary electrode. The potential value applied on the graphite electrode was measured against a micro reference electrode $(\mathrm{Ag} / \mathrm{AgCl})$ inserted into the auxiliary electrode. Palladium solutions in acetate buffer $\left(100 \mathrm{mmol} \mathrm{L}^{-1}, \mathrm{pH}=4.8\right)$, flowing at $0.5 \mathrm{~mL} \mathrm{~min}^{-1}$ for $60 \mathrm{~min}$ was used to perform the electrochemical modification. A mercury solution (1 ng) was used to evaluate the performance of the permanent palladium modifier.
\end{abstract}

Keywords: graphite tube flow cell; permanent modifier; atomic absorption spectrometry.

\section{INTRODUÇÃO}

O uso de modificadores químicos durante uma análise por espectrometria de absorção atômica com atomização eletrotérmica (ETAAS) é, na maioria das vezes, condição essencial para reduzir ou eliminar a volatilização do elemento de interesse e interferências na fase vapor ${ }^{1}$. O modificador químico converte o analito em uma forma menos volátil, permitindo maiores temperaturas de pirólise e/ou os concomitantes em uma forma mais volátil, promovendo a separação dos mesmos. Diversas substâncias vem sendo usadas como modificadores químicos, porém a mistura $\mathrm{Pd}+\mathrm{Mg}\left(\mathrm{NO}_{3}\right)_{2}$ ficou conhecida no começo dos anos 90 como o "modificador universal", por apresentar um bom desempenho para grande maioria dos elementos determinados por ETAAS ${ }^{2}$. Geralmente, altas concentrações da solução do modificador químico, de alta pureza, são acrescentadas às soluções analíticas de referência e às soluções das amostras com o auxílio de um amostrador automático. A solução do modificador químico também pode ser introduzida no tubo de grafite, sofrer um tratamento térmico adequado, promovendo a modificação da superfície grafítica para a amostragem da solução a ser analisada. Nesses casos, a modificação da superfície do tubo deve ocorrer antes de cada amostragem, se o elemento a ser determinado necessitar de altas temperaturas de atomização, o que provocaria a volatilização do modificador ${ }^{3}$. Se a temperatura de atomização utilizada for menor do que a temperatura de vaporização do modificador, diversas amostragens podem ser feitas com uma única modificação do tubo de grafite, tornando possível a execução de vários ciclos de aquecimento antes que um outro procedimento de modificação do tubo seja efetuado ${ }^{4-}$ ${ }^{7}$. Nesse caso o modificador é considerado permanente.

Além do processo térmico, sistemas eletroquímicos a potencial controlado ${ }^{8}$ e a corrente controlada ${ }^{9-12}$ também vem sendo utilizados para a modificação permanente da superfície de fornos de grafite ${ }^{7-10}$. Em todos os procedimentos eletroquímicos, utilizam-se células convencionais (em banho) em que o tubo de grafite é imerso na solução eletrolítica. Este

\footnotetext{
*e-mail: pvolivei@quim.iq.usp.br
}

procedimento acarreta, no entanto, a modificação da parede interna e externa do tubo de grafite. Em alguns casos, a superfície externa do tubo é protegida do contato eletrolítico com fita de PTFE?

Tubos de grafite com superfície modificada vem despertando interesse crescente na determinação de mercúrio por ETAAS em solução aquosa ${ }^{4,11}$ e com geração de vapor a frio $^{8}$, mediante pré-concentração e detecção após vaporização eletrotérmica. Os filmes de paládio ou ródio obtidos por eletrodeposição a partir de células convencionais (tubo de grafite como eletrodo de trabalho imerso na solução eletrolítica) foram utilizados na determinação de $\mathrm{Hg}$ em solução aquosa, suportando mais de 400 ciclos de aquecimento ${ }^{11}$.

Neste trabalho, apresenta-se uma célula eletroquímica tubular, robusta e de fácil construção que possibilita a modificação permanente da superfície interna do forno de grafite sob fluxo contínuo de solução.

\section{PARTE EXPERIMENTAL}

\section{A célula eletroquímica de fluxo}

A célula eletroquímica tubular desenvolvida para modificação de superfícies de tubos de grafite está apresentada na Figura 1A. Um tubo de grafite convencional de $19 \mathrm{~mm}$ de comprimento e $5,5 \mathrm{~mm}$ de diâmetro é usado como eletrodo de trabalho. A solução em fluxo contendo a espécie metálica de interesse é conduzida à célula através de um tubo de PTFE de $0,8 \mathrm{~mm}$ fixado sob pressão a uma das extremidades do tubo de grafite com o auxílio de um anel de silicone. Na extremidade oposta do tubo de grafite, posicionou-se um tubo de aço inoxidável de 2,5 $\mathrm{mm}$ de diâmetro interno e $10 \mathrm{~mm}$ de extensão que promove a saída da solução e opera como eletrodo auxiliar. O microeletrodo de referência de $\mathrm{Ag} / \mathrm{AgCl}^{13}$ (saturado com $\mathrm{NaCl}$ ), confeccionado sobre uma ponteira descartável de micropipeta de $10 \mu \mathrm{L}$ (Cole Parmer $\mathrm{n}^{\mathrm{o}}$ cat. 25710-06), foi inserido perpendicularmente ao fluxo de solução com o auxílio de um orifício de $1,5 \mathrm{~mm}$ de diâmetro efetuado sobre o eletrodo auxiliar. Um anel de silicone de $5 \mathrm{~mm}$ de extensão, posicionado sobre o tubo de aço inoxidável, assegura a fixação do eletrodo auxiliar junto ao canal da 
célula. Para evitar vazamento de solução, o orifício sobre o tubo de grafite $(\mathrm{d}=1,5 \mathrm{~mm})$, originalmente projetado para a introdução de soluções foi vedado com um fino tarugo de PVC fixado sob pressão com o auxílio de um tubo de silicone. O volume geométrico da célula (volume de solução necessário para unir os três eletrodos) é da ordem de $190 \mu \mathrm{L}$.

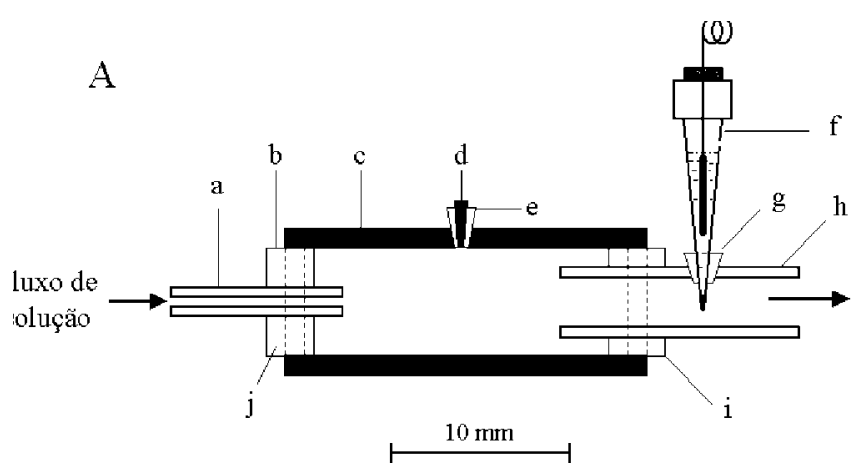

Figura 1. A. Diagrama esquemático da célula eletroquímica de fluxo: a) Tubo de PTFE; b), e), g), i) e j) Tubos de silicone; c) Eletrodo de trabalho (Tubo de Grafite); d) Cilindro de PVC; f) Eletrodo de referência; h) Eletrodo auxiliar.

\section{Instrumentação}

Os estudos voltamétricos com soluções de paládio em diferentes eletrólitos foram efetuados com um sistema eletroanalítico Autolab/GPES modelo PSG AT/20 Eco Chemie. Os experimentos para modificação do forno de grafite foram efetuados com a célula eletroquímica acima descrita combinada a um potenciostato de baixo custo desenvolvido no laboratório e centrado em amplificadores operacionais do tipo LF351. Os valores de potencial aplicados na célula eletroquímica e o valor do sinal de corrente que circula no eletrodo de trabalho foram monitorados por um mostrador digital de $3^{1 / 2}$ dígitos (resolução de $\pm 1 \mathrm{mV}$ ). $\mathrm{O}$ fluído transportador foi impulsionado por uma bomba peristáltica Ismatec modelo MS-REGLO. Um diagrama esquemático do sistema de fluxo empregado para modificação dos tubos de grafite é apresentado na Figura 1B. Os tempos de deposição para formação dos filmes metálicos foram controlados manualmente. Todas as modificações eletroquímicas foram efetuadas sob temperatura ambiente $\left(25 \pm 2^{\circ} \mathrm{C}\right)$.

$\mathrm{B}$

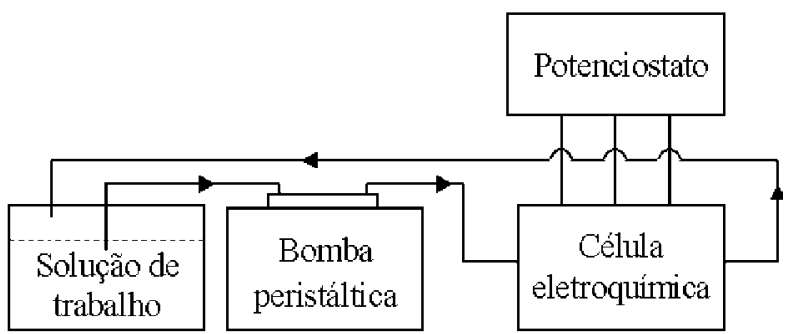

Figura 1. B. Diagrama do sistema de fluxo contínuo para a modificação de tubos de grafite.

Os filmes metálicos obtidos na superfície do tubo de grafite foram observados por Microscópio Eletrônico Panasonic, modelo GP-KR222.

Um espectrômetro de absorção atômica Analytik Jena-Carl Zeiss modelo AAS 6vario equipado com lâmpadas de cátodo oco de mercúrio do mesmo fabricante, forno de grafite com aquecimento transversal e corretor de fundo com lâmpada de deutério foi utilizado para as medidas espectroscópicas.

\section{Reagentes e Soluções}

Todas as soluções foram preparadas empregando água destilada e desionizada em sistemas de purificação do tipo Milli-Q. Os ácidos, $\mathrm{HNO}_{3}$ ou $\mathrm{HCl}$ (Merck) utilizados na preparação das soluções de referência e diluições, foram purificados por destilação abaixo do ponto de ebulição em subdestiladores de quartzo Marconi Equipamentos de Laboratório, modelo 075. Toda a vidraria e recipientes para armazenagem de soluções foram lavados com detergente, água destilada e guardados cheios com ácido nítrico $10 \%$ v/v. Antes de serem utilizados, a vidraria e os recipientes eram enxaguados com água desionizada.

Solução $1 \mathrm{mmol} \mathrm{L}^{-1}$ de paládio, $\mathrm{Pd}\left(\mathrm{NO}_{3}\right)_{2}$ (Merck), foi preparada em meio $100 \mathrm{mmol} \mathrm{L}^{-1}$ de tampão acetato $(\mathrm{pH}=4,8)$, $\mathrm{CH}_{3} \mathrm{COOH}$ e $\mathrm{CH}_{3} \mathrm{COO}^{-} \mathrm{Na}^{+}$(Merck). Soluções de $50 \mu \mathrm{g} \mathrm{L}^{-1}$ de $\mathrm{Hg}^{2+}$ em $\mathrm{HNO}_{3} 0,1 \% \mathrm{v} / \mathrm{v}$ ou $\mathrm{HCl} 0,1 \% \mathrm{v} / \mathrm{v}$ foram preparadas a partir de diluições sucessivas da solução estoque de $\mathrm{Hg}^{2+}$ $1000 \mathrm{mg} \mathrm{L}^{-1}\left(\mathrm{Hg}^{\mathrm{o}}\right.$ dissolvido em $\mathrm{HNO}_{3}$ concentrado).

\section{Metodologia}

A eletrodeposição de paládio sobre o grafite foi efetuada em potencial controlado de $-0,600 \mathrm{~V}$, medido em relação ao eletrodo de $\mathrm{Ag} / \mathrm{AgCl}$. As deposições foram efetuadas sob vazão de $0,5 \mathrm{~mL} \mathrm{~min}^{-1}$ durante 60 minutos.

Após a eletrodeposição o tubo de grafite foi introduzido no forno de grafite e submetido ao seguinte programa de aquecimento para condicionamento térmico (rampa, patamar): $90{ }^{\circ} \mathrm{C}\left(30^{\circ} \mathrm{C} / \mathrm{s} ; 15 \mathrm{~s}\right), 110^{\circ} \mathrm{C}\left(30^{\circ} \mathrm{C} / \mathrm{s} ; 15 \mathrm{~s}\right), 800^{\circ} \mathrm{C}\left(4^{\circ} \mathrm{C} / \mathrm{s} ; 10 \mathrm{~s}\right)$ e $2000{ }^{\circ} \mathrm{C}\left(50^{\circ} \mathrm{C} / \mathrm{s} ; 5 \mathrm{~s}\right)$.

Curvas de temperatura de pirólise para $20 \mu \mathrm{L}$ de $\mathrm{Hg}^{2+} 50 \mu \mathrm{g}$ $\mathrm{L}^{-1} \mathrm{em} \mathrm{HCl} 0,1 \% \mathrm{v} / \mathrm{v}$ foram obtidas na ausência e presença de paládio como modificador químico. O paládio foi empregado de três maneiras diferentes: adição de $10 \mu \mathrm{L}$ de solução contendo $5 \mu \mathrm{g}$ do metal juntamente com a solução aquosa de mercúrio, depositados térmica ou eletroliticamente sobre a superfície do tubo de grafite. O programa de aquecimento utilizado foi o seguinte (rampa, patamar): secagem $1=90^{\circ} \mathrm{C}(30 \mathrm{~s}, 20 \mathrm{~s})$; secagem $2=120^{\circ} \mathrm{C}(6 \mathrm{~s}, 10 \mathrm{~s}) ;$ pirólise $=250^{\circ} \mathrm{C}(13 \mathrm{~s}, 20 \mathrm{~s})$; atomização $=$ $1300{ }^{\circ} \mathrm{C}(0 \mathrm{~s}, 4 \mathrm{~s})$; limpeza $=1400^{\circ} \mathrm{C}(50 \mathrm{~s}, 2 \mathrm{~s})$. A temperatura de pirólise (Tp) foi variada de $100^{\circ} \mathrm{C}$ até $900^{\circ} \mathrm{C}$ para a obtenção das curvas de pirólise. $\mathrm{O}$ desempenho do modificador químico também foi avaliado com base no número de ciclos de aquecimento, da massa característica e do limite de detecção.

\section{RESULTADOS E DISCUSSÃO}

Embora o arranjo instrumental para a deposição sob corrente controlada seja mais simples (trabalha-se apenas com dois eletrodos e um galvanostato) e talvez por isso preferido por alguns autores $^{9-12}$ para a modificação permanente de fornos de grafite, a eletrodeposição sob controle potenciostático permite a deposição seletiva da espécie de interesse a partir da escolha criteriosa do valor do potencial aplicado à célula eletroquímica. No entanto, para assegurar o controle preciso do potencial na interface eletrodo-solução é necessário, além de um potenciostato, uma célula com baixa resistência interna e geometria que assegure a distribuição uniforme da corrente sobre o eletrodo de trabalho. Outro fator a ser considerado é o posicionamento do eletrodo de referência próximo ao eletrodo de trabalho e fora da região de circulação de corrente, entre o eletrodo de trabalho e o eletrodo auxiliar $^{14}$. Em células eletroquímicas tubulares em que os eletrodos são posicionados dentro do canal por onde flui a solução, a configuração eletroquímica ideal, muitas vezes, é sacrificada em favor de propriedades hidrodinâmicas favoráveis. Nesta célula, a junção microporosa do eletrodo de referência foi inserida junto ao eletrodo auxiliar, na saída da célula eletroquímica. $\mathrm{O}$ afastamento da idealidade foi tolerado a fim de assegurar que durante a etapa de finalização do processo de eletrodeposição a 


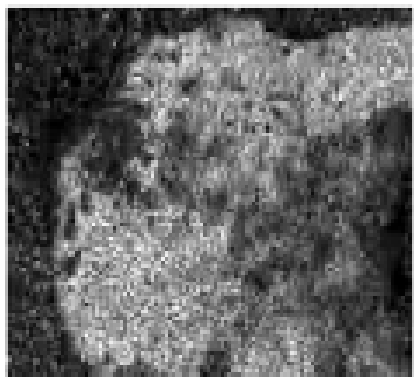

(a)

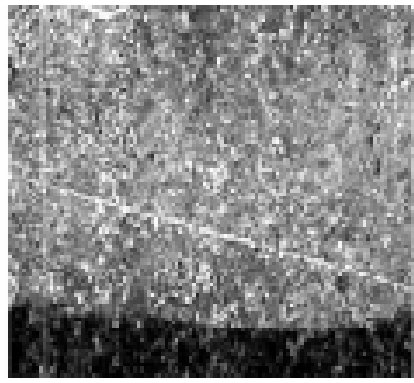

(b)

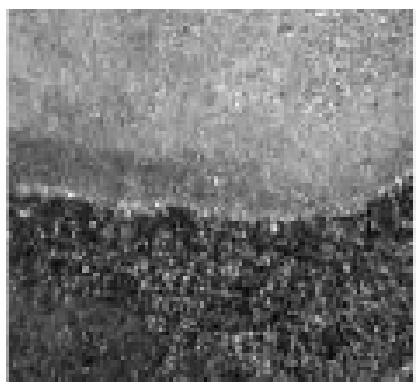

(c)

Figura 2. Microscopia eletrônica da superfície modificada do tubo de grafite após diferentes tempos de eletrodeposição de paládio: (a) 8 min.; (b) 15 min.; (c) 30 min. Fator de ampliação: 600 vezes; Concentração de paládio: 1 mmol $\mathrm{L}^{-1}$; Eletrólito suporte: tampão acetato 100 mmol $L^{-1}(\mathrm{pH}=4,8)$; Vazão: $0,5 \mathrm{~mL} \mathrm{~min}^{-1}$; Potencial de deposição: - 0,600 V vs Ag/AgCl (saturado com NaCl).

solução no interior do tubo de grafite fosse removida, através da aspiração de ar pela bomba peristáltica, sem a ocorrência de perturbação no potenciostato, evitando danos ou mesmo a remoção parcial do filme eletrodepositado. Na ocorrência da saturação do potenciostato (interrupção do contato eletrolítico entre os eletrodos auxiliar e de referência) efetua-se imediatamente a transferência dos eletrodos para uma célula de referência interna (posição de repouso do potenciostato).

A otimização do sistema para eletrodeposição foi efetuada a partir de estudos voltamétricos com solução de paládio $1 \mathrm{mmol}$ $\mathrm{L}^{-1}$ em tampão acetato $100 \mathrm{mmol} \mathrm{L}^{-1}(\mathrm{pH}=4,8)$ utilizado como eletrólito suporte. Na escolha deste eletrólito considerou-se a concentração hidrogeniônica necessária para evitar a hidrólise do íon Pd(II) e a faixa útil de trabalho do eletrodo de grafite na região negativa de potencial (limitada pela descarga do íon $\mathrm{H}^{+}$em meio ácido). $\mathrm{O}$ valor do potencial de trabalho selecionado $(-0,600 \mathrm{~V}$ vs $\mathrm{Ag} / \mathrm{AgCl})$ correspondeu a região de potencial em que se assegura a redução do $\mathrm{Pd}(\mathrm{II})$ a $\mathrm{Pd}(0)$, sem ocorrência de descarga significativa dos íons $\mathrm{H}^{+}$.

A inspeção visual da parede interna do tubo de grafite, após recobrimento por eletrodeposição durante 8,15 e $30 \mathrm{~min}$, sob vazão de $0,5 \mathrm{~mL} \mathrm{~min}{ }^{-1}$ de paládio, foi feita através de ampliação por microscopia eletrônica (Figura 2). As manchas de cor cinza claro, ilustradas na Figura 2 (a), (b) e (c), representam o paládio depositado eletroquimicamente. Essas ampliações revelaram que filmes homogêneos podem ser obtidos após 30 minutos de eletrólise, Figura 2 (c). O sinal de absorbância de $\mathrm{Hg}^{2+} 50 \mu \mathrm{g} \mathrm{L}$ ${ }^{1}$ em $\mathrm{HNO}_{3} \quad 0,1 \% \mathrm{v} / \mathrm{v}$ foi constante acima de $50 \mu \mathrm{g}$ de paládio depositado sobre o tubo de grafite. Porém, para garantir a formação de um filme mais espesso, que aumentou a vida útil da superfície modificada, proporcionando mais ciclos de aquecimento, o tempo de eletrólise utilizado foi de $60 \mathrm{~min}$. Nas condições adotadas para a eletrólise, a corrente gerada foi de $550 \mu \mathrm{A}$.

$\mathrm{O}$ condicionamento térmico do tubo de grafite após a modificação por eletrodeposição foi necessário para aumentar a estabilidade térmica do paládio e diminuir a radiação de fundo observada nas primeiras queimas, provavelmente provocada pela evaporação de espécies de paládio e pela umidade do tubo. Quando esta etapa não foi executada o número de ciclos de aquecimento suportado pelo filme e a sensibilidade foram prejudicados. Provavelmente compostos de intercalação são formados entre o grafite e o paládio durante o condicionamento térmico ${ }^{15}$.

As curvas de pirólise obtidas com soluções aquosas mostraram que na ausência do modificador químico (Figura 3a) as perdas por volatilização ocorreram progressivamente a partir de $120^{\circ} \mathrm{C}$. No entanto, quando $10 \mathrm{~mL}$ de solução contendo paládio $500 \mathrm{mg}$ $\mathrm{L}^{-1}$, foi introduzida simultaneamente com a solução analítica de mercúrio (Figura 3b), perdas do analito por volatilização ocorreram a partir de $120^{\circ} \mathrm{C}$, com a formação de um patamar que se estendeu até $350^{\circ} \mathrm{C}$, indicando a formação de algum composto estável nesta região de temperatura. Nessa condição, entre $120^{\circ} \mathrm{C}$ e $350^{\circ} \mathrm{C}$, a perda de sensibilidade foi de $20 \%$. Por outro lado, na presença do modificador químico de paládio, depositado eletroliticamente (Figura 3c) ou termicamente (Figura 3d), as temperaturas de pirólise suportadas pelo mercúrio foram de $250^{\circ} \mathrm{C}$. O mecanismo envolvido para a estabilização térmica do mercúrio deve estar relacionado a formação de compostos intermetálicos com o paládio ${ }^{5}$. As massas características obtidas com o tubo de grafite modificado térmica ou eletroliticamente foram $151 \mathrm{pg}$ e $150 \mathrm{pg}$, respectivamente. Esses valores de massas características são melhores do que aqueles reportadas na literatura ${ }^{11}$, com os cálculos feitos a partir de $20 \mathrm{~mL}$ de solução, com o modificador de paládio obtido térmica $(230 \mathrm{pg})$ ou eletroliticamente $(220 \mathrm{pg})$. $\mathrm{O}$ número de ciclos de aquecimento, para temperaturas de limpeza de $1400^{\circ} \mathrm{C}$ foi de $50(\mathrm{RSD}=1,0 \%)$ e superiores a $400(\mathrm{RSD}$ $=1,5 \%$ ) para o tubo recoberto termicamente com $50 \mathrm{mg}$ e eletroquimicamente com $1000 \mathrm{mg}$ de paládio, respectivamente. O maior número de ciclos de aquecimento suportado pelo modificador permanente, obtido por eletrólise, pode ser devido a maior massa do paládio depositada ${ }^{5}$.

\section{CONSIDERAÇÕES FINAIS}

A célula eletroquímica proposta é robusta e facilmente implementada para a modificação homogênea da parede interna de tubos de grafite com aquecimento longitudinal e transversal, podendo ser utilizada com soluções em fluxo ou com soluções em regime estacionário.

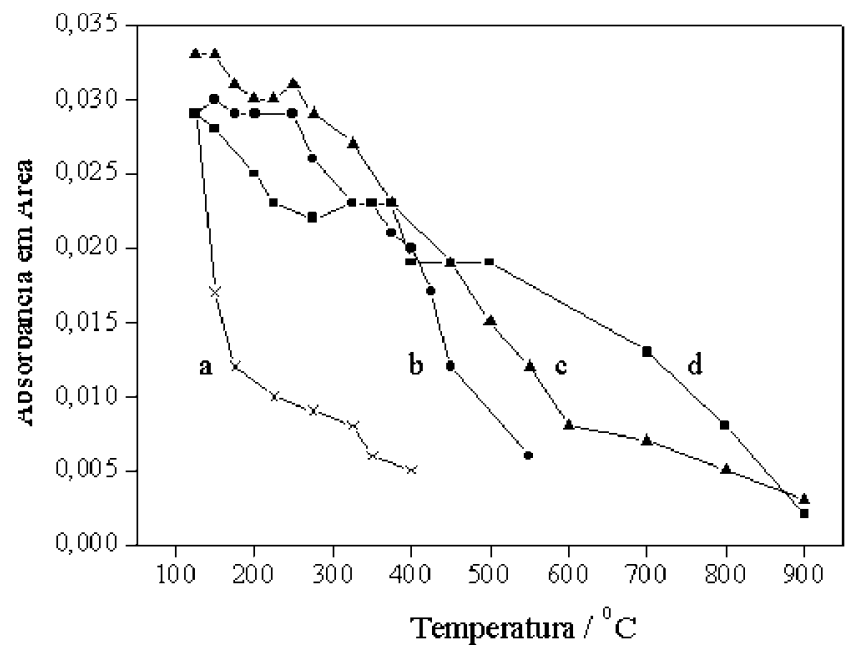

Figura 3. Curvas de temperatura de pirólise de $\mathrm{Hg}^{2+} 1 \mathrm{ng}$ em diferentes condições, fixando a temperatura de atomização em $1300^{\circ} \mathrm{C}$ : (a) Sem modificador; (b) Com modificador de paládio adicionado junto com a solução; (c) Modificador permanente de paládio eletroquimicamente depositado; (d) Modificador permanente de paládio termicamente depositado. 
Embora as sensibilidades para soluções aquosas de mercúrio, expressa em termos das massas características $\left(m_{\mathrm{o}}\right)$, sejam comparáveis, os filmes de paládio obtidos eletroliticamente permitiram maior número de ciclos de aquecimento (acima de 400) do que aqueles obtidos termicamente (50).

Resultados preliminares envolvendo a pré-concentração de mercúrio obtido por geração de vapor a frio mostraram-se promissores, dispensando as tradicionais colunas de ouro utilizadas nos sistemas convencionais com a finalidade de melhorar o limite de detecção, simplificando o sistema.

Além do paládio, outros elementos metálicos podem ser utilizados para modificação da parede interna de tubos de grafite, tais como: $\mathrm{Rh}$, a mistura $\mathrm{Rh} / \mathrm{Pd}$ e a mistura W/Rh.

\section{AGRADECIMENTOS}

Os autores agradecem à Fundação de Amparo à Pesquisa do Estado de São Paulo (FAPESP - Processo 99/0970-0) pelo suporte financeiro. Rubén Gregorio Moreno Moreno agradece a (CNPq - Processo 136583/99-7) pela bolsa de mestrado e Pedro Vitoriano de Oliveira agradece à Fundação de Amparo à Pesquisa do Estado de São Paulo (FAPESP - Processo 98/ 05134-3) pelas bolsa de pós-doutorado.

\section{REFERÊNCIAS}

1. Welz, B.; Sperling, M.; Atomic Absorption Spectrometry
- $3^{\text {rd }}$ ed, Completely Revised Edition, Wiley - VCH; Weinheim, 1999; p 411.

2. Welz, B.; Schelemmer, G.; Mudakavi, J. R.; J. Anal. At. Spectrom. 1992, 7/8, 1257.

3. Moreira, F. R.; Pivetta, F.; At. Spectrosc. 1998, 19, 137.

4. Welz, B.; Schelemmer, G.; Mudakavi, J. R.; J. Anal. At. Spectrom. 1992, 7/8, 499.

5. Bermejo-Barrera, P.; Moreda-Pinero, J.; Moreda-Pinero, A.; Bermejo-Barrera, A.; J. Anal. At. Spectrom. 1997, 12, 317.

6. Lima, E. C.; Krug, F. J.; Jackson, K. W.; Spectrochim. Acta - Part B 1998, 53, 1791.

7. Murphy, J.; Schlemmer, G.; Shuttler, I. L.; Jones, P.; Hill, S. J.; J. Anal. At. Spectrom. 1999, 14, 1593.

8. Batley, G. E.; Matousek, J. P.; Anal. Chem. 1977, 49, 2031.

9. Lee, S. H.; Jung, K; Lee, D. S.; Talanta 1981, 36, 999.

10. Shiowatana, J.; Matousek, J. P.; Talanta 1991, 38, 375.

11. Bulska, E.; Kandler, W.; Hulanicki, A.; Spectrochim. Acta - Part B 1996, 51, 1263.

12. Bulska, E.; Liebert-Ilkowaka, K.; Hulanicki, A.; Spectrochim. Acta - Part B 1998, 53, 1957.

13. Pedrotti, J. J.; Agnes, L.; Gutz, I. G. R.; Electroanalysis 1996, 8, 673.

14. Stulik, K.; Pacákova, V., Electroanalytical Measurements in Flowing Liquids, Ellis Horwood, Chichester, 1987; p 111.

15. Volynsky, A. B.; Spectrochim. Acta - Part B 2000, $55,103$. 